\title{
First record of molluscs naturally infected with Angiostrongylus cantonensis (Chen, 1935) (Nematoda: Metastrongylidae) in Brazil
}

\author{
Roberta Lima Caldeira, Cristiane LGF Mendonça/*, Christiane Oliveira Goveia, \\ Henrique L Lenzi**, Carlos Graeff-Teixeira***, Walter S Lima****, Ester M Mota**, \\ Iracy Lea Pecora ${ }^{* * * * *}$, Aline Maria Zigiotto de Medeiros*****, Omar dos Santos Carvalho/ ${ }^{+}$
}

\begin{abstract}
Laboratório de Helmintoses Intestinais, Instituto René Rachou-Fiocruz, Av. Augusto de Lima 1715, 30190-002 Belo Horizonte, MG, Brasil *Pontifícia Universidade Católica de Minas Gerais **Laboratório de Patologia, Instituto Oswaldo Cruz-Fiocruz, Rio de Janeiro, RJ, Brasil

***Laboratório de Parasitologia Molecular, Pontifícia Universidade Católica do Rio Grande do Sul, Porto Alegre, RS, Brasil ****Departamento de Parasitologia, Instituto de Ciências Biológicas, Universidade Federal de Minas Gerais, Belo Horizonte, MG, Brasil *****Universidade Estadual Paulista, Campus do Litoral Paulista, Unidade São Vicente, SP, Brasil
\end{abstract}

Seeking the identification of Angiostrongylus cantonensis as a potential etiological agent of three clinical cases of eosinophilic meningitis, mollusc specimens were collected in the state of Espirito Santo, Brazil. The snails were identified as Sarasinula marginata (45 specimens), Subulina octona (157). Achatina fulica (45) and Bradybaena similaris (23). Larvae obtained were submitted to polymerase chain reaction and restriction fragment length polymorphism diagnosis. Their genetic profile were corresponded to A. cantonensis. Rattus norvegicus experimentally infected with third-stage larvae, developed menigoencephalitis, and parasites became sexually mature in the lungs. Additionally, larvae obtained from A. fulica snails, from São Vicente, state of São Paulo, also showed genetic profiles of this nematode. This is the first record of Brazilian molluscs infected with this nematode species.

Key words: Angiostrongylus cantonensis - terrestrial molluscs - Brazil

Nineteen species of Metastrongylidae of the genus Angiostrongylus are recognized worldwide, two of which may cause human infection namely Angiostrongylus cantonensis (Chen, 1935) and A. costaricensis Morera $\&$ Céspedes, 1971. The former is identified as one of the etiological agents of eosinophilic meningoencephalitis (Alicata 1962), and the latter is the etiological agent of abdominal angiostrongyliasis (Morera \& Céspedes 1971).

A. cantonensis has already been found in Southeast Asia, South Pacific, Africa, India, Caribbean, Australia, North America (Pien \& Pien 1999), Jamaica (Lindo et al. 2002) and Haiti (Raccurt et al. 2003).

Eosinophilic meningitis is a rare clinical entity that is defined by the presence of 10 or more eosinophils/ $\mathrm{ml}$ in the cerebrospinal fluid (CSF) or a CSF eosinophilia of at least $10 \%$ of the total CSF leukocyte count (Kuberski 1979). The most common cause is invasion of the central nervous system by helminthic parasites, inciting an inflammatory response that eventually kills the parasites. Clinical manifestations, which develop in humans at two to 35 days after larvae ingestion, may include headache, nuchal rigidity and visual disturbances (Koo et al. 1988). Cerebral angiostrongyliasis usually has an incubation period of about two weeks, although it

Financial support: Fiocruz, Secretaria de Vigilância em Saúde (Brazilian Ministry of Health)

${ }^{+}$Corresponding author: omar@cpqrr.fiocruz.br

Received 30 May 2007

Accepted 31 October 2007 may vary from 12 to 28 days (Dooley \& Neafie 1976). Paresthesias of the extremities, trunk or face, are the most distinctive neurological findings and can persist for weeks to months after the other symptoms are resolved. Occasionally, infective larvae can migrate to the eye, causing retinal detachment or intraocular hemorrhage, but most patients recover completely (Alicata 1962, Sawanyawisuth et al. 2007). In Brazil, a clinical case of eosinophilic meningoencephalitis that resulted in death ten days after ingestion of three Achatina fulica snails was reported in a regional meeting in 2006 (AVS Moll, G Zanini and C Graeff-Teixeira, unpublished observations).

In January 2007, two male individuals aged 21 and 39 years were admitted to the local hospital of Cariacica, state of Espírito Santo (ES), Brazil, with eosinophilic meningitis and history of ingestion of raw terrestrial slugs. By that time, a male child aged one year and eight months from the city of Vila Velha, ES, had also been admitted to the hospital with similar symptoms.

A number of 270 mollusc specimens and feces from Rattus norvergicus were collected with a grasping tool, in peridomiciliary areas of the patients' houses by health agents of the Central Laboratory of the ES (LACEN-ES). The materials were sent to the Laboratory of Intestinal Helminthiasis of Instituto René Rachou-Fiocruz for mollusc morphological identification and molecular characterization of nematode larvae. The gastropods were identified as: Sarasinula marginata (Semper, 1885) (Veronicellidae), 45 specimens, Subulina octona (Bruguière, 1792) (Subulinidae), 157 specimens, A. fulica (Bowdich, 1822) (Achatinidae), 45 specimens, and Bradybaena similaris (Férussac, 1821) (Bradybaenidae), 23 specimens. 
The digestion procedure of molluscs in laboratory was done according to procedure proposed by Wallace \& Rosen (1969) followed by Baermann sedimentation method (Moraes 1948). After sedimentation, the material was analyzed under a stereomicroscope for detection of nematode larvae. Second- and third-stage nematode larvae $\left(\mathrm{L}_{2}\right.$ and $\left.\mathrm{L}_{3}\right)$ were detected in the snail specimens. Twenty seven out of 45 S. marginata specimens were highly infected (approximately $500 \mathrm{~L}_{3} / \mathrm{slug}$ ), 10 harbored approximately $20 \mathrm{~L}_{3}$, one dead slug presented only three $\mathrm{L}_{2}$ and seven were negative. Remarkably, some slugs contained more than 2,000 larvae. From 157 S. octona specimens analyzed, 120 were infected with both $\mathrm{L}_{2}$ and $\mathrm{L}_{3}$ (average of 20 larvae/mollusc). Thirty A. fulica and all B. similaris specimens were also found highly infected (approximately $1,000 \mathrm{~L}_{3} / A$. fulica, and 300 $\mathrm{L}_{3} /$ B. similaris).

Larvae from two specimens of $S$. marginata were used to infect three $R$. norvegicus, Wistar strain $\left(100 \mathrm{~L}_{3}\right.$ /rodent). Nematode larvae were also isolated from $R$. norvergicus' feces and, like those larvae obtained from molluscs, were submitted to molecular analysis. DNA extraction was undertaken with kit DNA Wizard Genomic Purification (Promega, Madison, USA), according to the manufacturer's instructions. For comparison, other nematodes were also included in the study: A. cantonensis (Department of Parasitology, Medical School, Akita University, Japan), A. costaricensis (Laboratório de Patologia, Instituto Oswaldo Cruz, RJ, Brazil) and A. vasorum (Baillet, 1966) (Departamento de Parasitologia, Universidade de Minas Gerais, MG, Brazil), which had been stored (-70 C). Polymerase chain reaction and restriction fragment length polymorphism (PCR-RFLP) directed to the internal transcribed spacer 2 (ITS2) region were carried out using the restriction enzyme Cla I (Caldeira et al. 2003). The genetic profiles generated by the larvae pool in all studied molluses species and rat fecal material are shown in the Figure 1. High intensity fragments can be observed due to the presence of a high number of larvae obtained from molluscs.

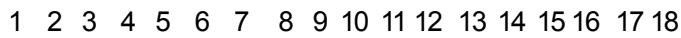

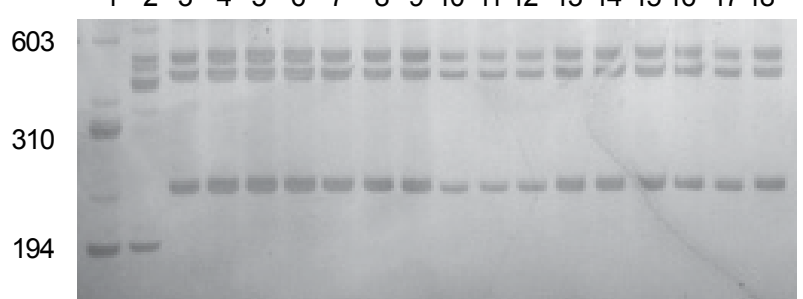

Fig.1: silver stained polyacrylamide gel (6\%) shows PCR-RFLP profiles of the ITS2 of rDNA with the enzyme ClaI. Lane $-1: \mathrm{L}_{1}$ pool of Angiostrongylus vasorum (Caratinga, MG, Brazil); 2: adult worm of $A$. costaricensis (Rio de Janeiro, RJ, Brazil); 3: adult worm of A. cantonensis (Akita, Japan); 4, 5: $\mathrm{L}_{3}$ pool obtained from Sarasinula marginata (Cariacica, ES, Brazil); 6, 7: $\mathrm{L}_{3}$ pool obtained from Subulina octona (Cariacica); 8, 9: $\mathrm{L}_{3}$ pool obtained from Achatina fulica (Cariacica); 10, 11: $\mathrm{L}_{3}$ pool obtained from Bradybaena similaris (Cariacica); 12, 13: $\mathrm{L}_{1}$ pool obtained from feces from Rattus norvegicus (Cariacica); $14-16: \mathrm{L}_{3}$ pool obtained from $A$. fulica (São Vicente, SP, Brazil); 17, 18: A. cantonensis (Akita, Japan). Molecular size markers are shown in the left side of the figure.
One $R$. norvegicus was killed at 25 days of infection and the other two at 57 days post-infection (p.i.) and all the organs were removed and fixed in Carson's formalin-Millonig (Carson et al. 1973). Haematoxylin-eosin stained sections of the brain, heart, lungs, intestine, liver, pancreas, spleen, kidneys, and female genital tract were examined. The rat that killed at 25 days p.i. presented large number of young adult worms in dilated and thick meningeal veins and the meninges were infiltrate with macrophages, less number of lymphocytes, plasma cells and few eosinophils. These were present in larger number in small intracerebral granulomatous reactions. Eventually, the inflammatory infiltrate extended to perivascular space of intracerebral vessels, characterizing an encephalitic component (Fig. 2). Otherwise, the two rats that killed at 57 days p.i. presented meninges almost normal, presence of mature male and female adult worms in the lumen of pulmonary artery and lungs full of granulomatous reactions, containing large number of eggs with larvogenesis (Fig. 3).

Additionally, nematode larvae obtained from A. fulica snails, collected in São Vicente, state of São Paulo and received from the University Campus of Litoral Paulista, Universidade do Estado de São Paulo (UNESP), were also submitted to molecular characterization. The larvae genetic profile was compatible with that of $A$. cantonensis of Japan (Fig. 1, lanes 3, 17, and 18).

The molecular profile (Caldeira et al. 2003) and the behavior of the parasite in $R$. norvegicus strongly guarantee the diagnosis of $A$. cantonensis instead of $A$. costaricensis. This only presents transient passage to the brain and lungs and finally mature in mesenteric arteries (Mota \& Lenzi 1995, 2005, Serra et al. 2003), while the A. cantonensis larvae molt twice in the meningeal vessels developing to young adult worms, becoming sexually mature in the pulmonary vasculature.

The present report on the introduction of $A$. cantonensis in Brazil leads to an alert to physicians and public health workers for the consideration of this helminth, among many other parasitic and non-infectious causes, in the differential diagnosis of eosinophilic meningitis.

A. cantonensis has been probably introduced in Brazil through migrating rats within ships. Such hypothesis is supported by the fact that the municipalities of Cariacica, Vila Velha (state of Espírito Santo) and São Vicente (state of São Paulo) constitute important commercial ports with intense shipments. Such dispersion mechanism was also observed by Kliks and Palumbo (1992) in the Pacific basin.

This is the first report of molluscs infected with $A$. cantonensis in Brazil and South America as well as the first finding of $S$. marginata naturally infected with this nematode. S. octona, A. fulica and B. similaris had already been described as natural intermediate hosts of $A$. cantonensis in Africa and the Pan-Pacific region (Malek \& Cheng 1974, Kliks \& Palumbo 1992). The promiscuous capacity of Metastrongylidae of infecting several species of molluscs is a great risk to its spreading throughout different parts of the country. 


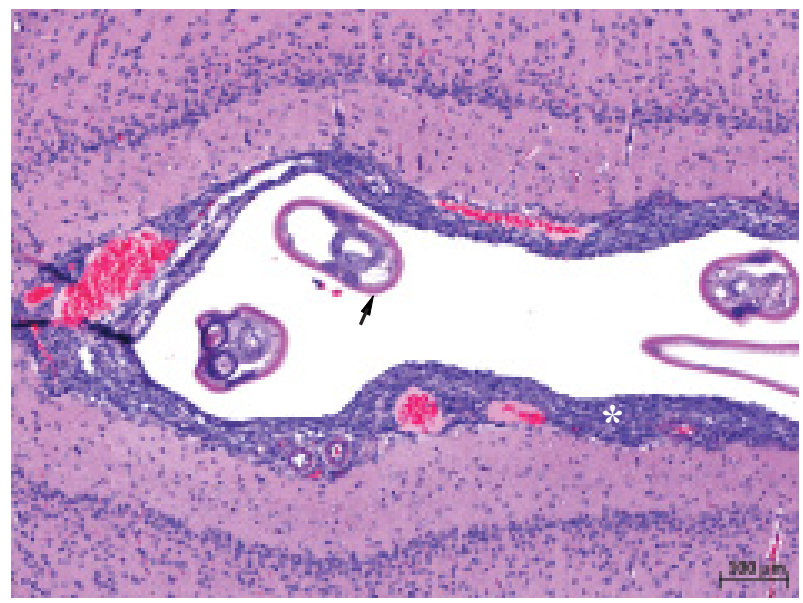

Fig. 2: Angiostrongylus cantonensis young adult worms (arrow) associated with meningitis, consisting of vascular congestion and intense macrophage infiltration (asterisk), with less number of lymphocytes (Rattus novergicus at 25 days post-infection) (HE, 100x).

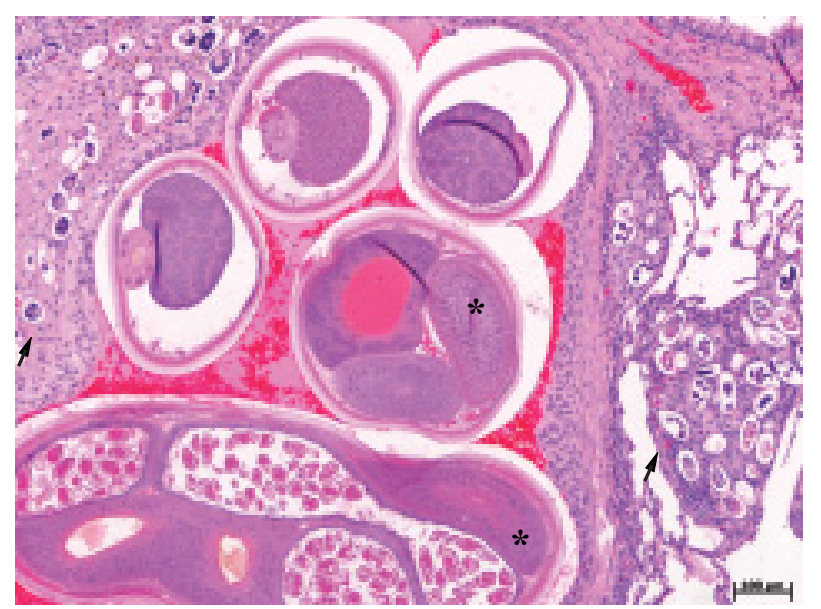

Fig. 3: presence of mature Angiostrongylus cantonensis male and female adult worms (asterisk) in the lumen of the pulmonary artery and adjacent lung full of granulomatous reactions, around a large number of eggs undergoing larvogenesis (arrow) (Rattus novergicus at 57 days post-infection) (HE, 100x).

\section{ACKNOWLEDGEMENTS}

To Dr Kentaro Yoshimura (Department of Parasitology, Medical School of University of Akita, Japan), for providing A. cantonensis. To Elizabeth Bessa and Sthefane D'Ávila from Universidade Federal de Juiz de Fora for confirming species identification of Subulina octona. To Janaína Guedes for technical support.

\section{REFERENCES}

Alicata JE 1962. Angiostrongylus cantonensis (Nematoda: Metastrongylidae) as a causative agent of eosinophilic meningits of man in Hawaii and Tahiti. Can J Zool 40: 5.

Anderson RC 2000. Nematode Parasites of Vertebrates: Their development and transmission, 2nd ed., CAB Internacional, Wallingford, UK, $650 \mathrm{pp}$

Caldeira RL, Carvalho OS, Mendonça CLF, Graeff-Teixeira C, Silva MCF, Ben R, Maurer R, Lima WS, Lenzi HL 2003.
Molecular differentiation of Angiostrongylus costaricensis, A. cantonensis, and A. vasorum by Polymerase Chain Reaction and Restriction Fragment Length Polymorphism. Mem Inst Oswaldo Cruz 98: 1039-1043.

Carson FL, Martin JH, Lynn JA 1973. Formalin fixation for electron microscopy: Are-evaluation. Am J Clin Pathol 59: 365-373.

Dooley JR, Neafie RC 1976. Angiostrongylus cantonensis infections. In C H Bindford, DH Connor, Pathology of Tropical and Extraordinary Diseases, Vol 2, Armed Forces Institute of Pathology, Washington, DC, p. 446-451.

Kliks MM, Palumbo NE 1992. Eosinophilic meningitis beyond the Pacific Basin: The global dispersal of a peridomestic zoonosis caused by Angiostrongylus cantonensis, the nematode lungworm of rats. Soc Sci Med 34: 199-212.

Koo J, Pien FD, Kliks MM 1988. Angiostrongylus (Parastrongylus) eosinophilic meningitis. Rev Infect Dis 10: 1155-1162.

Kuberski T 1979. Eosinophils in the cerebrospinal fluid. Ann Inter Med 91: 70-75.

Lindo JF, Waugh C, Hall J, Cunningham-Myrie C, Ashley D, Eberhard ML, Sullivan JJ, Bishop HS, Robinson DG, Holtz T, Robinson RD 2002. Enzootic Angiostrongylus cantonensis in rats and snails after an outbreak of human eosinophilic meningitis, Jamaica. Emerg Infect Dis 8: 324-326.

Malek EA, Cheng TC 1974. Medical and economic malacology. Academic Press, New York, NY, 398 pp.

Moraes RG 1948. Contribuição para o estudo do Strongyyloides stercoralis e da estrongiloidose no Brasil. Rev Serv Esp Saúde Públ 1: 507-624.

Morera P, Céspedes R 1971. Angiostrongilosis abdominal. Una nueva parasitosis humana. Acta Méd Costarric 14: 159-173.

Mota EM, Lenzi HL 1995. Angiostrongylus costaricensis life cycle: a new proposal. Mem Inst Oswaldo Cruz 90: 707-709.

Mota EM, Lenzi HL 2005. Angiostrongylus costaricensis: complete redescription of the migratory pathaways based on experimental Sigmodon hispidus infection. Mem Inst Oswaldo Cruz 100: 407-420.

Pien FD, Pien BC 1999. Angiostrongylus cantonensis eosinophilic meningitis. Int J Infect Dis 3: 161-163.

Raccurt CP, Blaise J, Durette-Desset MC 2003. Presence of Angiostrongylus cantonensis in Haiti. Trop Med Int Health 8: 423-426.

Sawanyawisuth K, Kithaweesi K, Limpawattana P, Intapan PM, Tiamkao S, Jitpimolmard S, Chotmongkol V 2007. Intraocular angiostrongyliasis: clinical findings, treatments and outcomes. Trans R Soc Trop Med Hyg 101: 497-501.

Serra MF, Barreto EO, Silva JP, Azevedo V, Mota EM, PelajoMachado M, Lucena S, Pires AL, Carvalho V, Cordeiro RS, Lenzi HL, Silva PM, Martins MA 2003. Kinetics of eosinophil and IgE-mast cell changes following infection with Angiostrongylus costaricensis in Wistar rats. Parasite Immunol 25: 169-177.

Wallace GD, Rosen L 1969. Techniques for recovering and identifying larvae of Angiostrongylus cantonensis from molluscs. Malacologia 7: 427-438.

Yousiff, Lämmler G 1975. The suitability of several aquatic snails as intermediate hosts for Angiostrongylus cantonensis. $Z$ Parasitenk 47: 203-210. 